Linha D'Água (Online), São Paulo, v. 30, n. 2, p. 17-34, out. 2017

\title{
O PAPEL DO LEITOR EM FELPO FILVA, DE EVA FURNARI
}

\section{THE ROLE OF READER IN FELPO FILVA, BY EVA FURNARI}

\author{
Ana Elvira Luciano Gebara* \\ Universidade Cruzeiro do Sul e Fundação Getúlio Vargas, São Paulo, SP, Brasil \\ Magali Sparano** \\ Universidade Cruzeiro do Sul, São Paulo, SP, Brasil
}

Resumo: Para se analisar a relaçã̃o entre escritor-leitor além da mediação do texto, é preciso identificar as posiçōes que ocupam. Antes da internet, não era comum o leitor se aproximar diretamente do escritor, salvo por cartas. Esse contato virtual (mas ñ̃o digital) é modelar para compreendermos a relação do leitor com 0 autor pois, nas linhas escritas, aquele acaba por indicar como compreende a si e ao outro - em um jogo das faces, entendida nesse trabalho como Kerbrat-Orecchioni (2006) a caracteriza na conversaçacão. Nesse hipergênero, sem restriç̦ẽes sócio-históricas e de categorização (MAINGUENEAU, 2010), há uma disposiçãoo obrigatória que constrange o remetente a identificar sua posição a partir do momento em que escolhe como se dirigir ao destinatário. Nessas formas de tratamento, comecçam a ser delineadas as relaçōes de preservação ou de ameacça à face que se estendem ou se explicitam no tratamento dado ao tema da carta. Nesse artigo, tem-se como objetivo identificar, nas cartas trocadas pelos personagens centrais para o desenvolvimento da narrativa do livro Felpo Filva (FURNARI, 2006), Charlô e Felpo, respectivamente leitora e escritor, as concepções desses papeis nos nossos dias na perspectiva discursivo-dialógica em que os limites do texto para o leitor são ultrapassados.

Palavras-chave: hipergênero carta; papel do leitor; literatura infantil; Felpo Filva; FTA e FFA.

\begin{abstract}
In order to analyze the relationship between writer-reader and mediation of the text, it is necessary to identify the positions they occupy. Before the Internet, it was not common for the reader to approach the writer directly, except though letters. This virtual (but not digital) contact is modelling to understand the reader's relationship with the author because, in the written lines, he ends up indicating how he understands himself and the other - in a game of faces, understood in this work as Kerbrat-Orecchioni (2006) it characterizes in conversation. In this hyper-gender, without socio-historical restrictions or of categorization (MAINGUENEAU, 2010), there is a mandatory provision that constrains the sender to identify his position from the moment he chooses how to address the recipient. In these forms of treatment, the relationships of preservation or threat to the in the light of what is extended or made explicit in the treatment given to the theme of the letter to be outlined. This article aims to identify the concepts of the reader in the correspondence exchanged by the main characters, Charlo and Felpo, core of the development of the narrative (FURNARI, 2006). These concepts allow us to comprehend, in a discursive and dialogical perspective, which boundaries remain for the reader towards the text and which are outdated.
\end{abstract}

Keywords: Hyper-Genre Letter; Role of Reader; Children's Literature; Felpo Filva; Politeness.

* Professora doutora da Universidade Cruzeiro do Sul - Unicsul e Fundação Getúlio Vargas - FGV, São Paulo, SP, Brasil; aegebara@hotmail.com

* * Professora doutora da Universidade Cruzeiro do Sul - Unicsul, São Paulo, SP, Brasil; magalisparano@gmail.com 
Linha D'Água (Online), São Paulo, v. 30, n. 2, p. 17-34, out. 2017

\section{Introdução}

Presentes em todas as línguas ${ }^{1}$ a (des)cortesia é condicionada pelas relações entre falante e ouvinte, pois, como os estudos do discurso indicam, as interações, pela sua natureza dialógica, trazem, para os eventos comunicativos, a posição de cada um desses participantes, as imagens que projetam sobre si mesmos e sobre o outro - o que faz presente também o contexto sócio-histórico. Esses elementos regulam ainda o tratamento dispensado ao tema pelo entorno; o que configura, a cada um desses contextos e relações entre os interlocutores, novas combinações de interpretação do que seja (des)cortês e de seus papeis.

Fuentes (apud Bénitez, 2011) indica que as formas serão consideradas corteses ou descorteses a partir da análise dos seguintes elementos:

1) o elemento linguístico;

2) o cotexto;

3) o tipo de discurso;

4) o contexto em sentido amplo.

Dentro desses elementos condicionantes, uma matriz significativa do funcionamento da (des)cortesia são os gêneros textuais pelas percepções sociais que os constituem e que eles implicam, principalmente a relação estabelecida pelos participantes no gênero e aos participantes pelo gênero.

Sejam orais ou escritos, os gêneros envolvidos na comunicação auxiliam as pesquisas sobre a (des)cortesia, uma vez que, em cada um deles, é possível segundo convenções, funções, estruturas composicionais, relação entre os participantes já de antemão resultantes do modo como o gênero (cena genérica) se insere no domínio discursivo, prever certos posicionamentos e ações. Isso se relaciona com o conceito apresentado por Briz (apud BENÍTEZ, 2011), da "cortesia codificada”, que seria prévia e regulada pelos gêneros e correspondente a convenções. Ao lado do que é

1 Cf. KERBRAT-ORECCHIONI, C. ¿̇Es universal la cortesía? Tradução espanhol de Silvia Kaul de Marlangeon. In BRIZ, A.; BRAVO, D. Pragmática Sociocultural: Estudios sobre el discurso de la cortesía em español. Barcelona: Ariel, 2004. 
Linha D'Água (Online), São Paulo, v. 30, n. 2, p. 17-34, out. 2017

prévio e se encontra dentro do universo de expectativas de um regime genérico, encontra-se a "cortesia interpretada”, (BRIZ apud BENÍTEZ, 2010, p. 4):

(....) es uma estrategia linguística interaccional, evaluable contexto a contexto, a cada momento, de acuerdo con los inicios y, sobre todo, reacciones de los participantes en la interacción. Para la evaluación de la cortesía verbal propone unos filtros evaluadores y de interpretación, que son activados, desactivados o jerarquizados a lo largo de la interacción: +/- solidaridad entre los interlocutores, +/- fin interpersonal de la interacción, + /- pertinencia de ideomas, + /- problematicidad temática y +/- aceptación linguística social" (A. Briz 2004: 79). De este análisis se concluye que, aunque una forma linguística puede aparecer asociada a una estrategia cortés o descortés, el efecto en la interpretación puede variar, ya sea manteniendo o incluso potenciando el valor cortés o descortés, ya sea desactivando tal estrategia de modo que deja de ser interpretada como mecanismo cortés o descortés, como sucede, por ejemplo, en el habla coloquial entre amigos jóvenes. ${ }^{2}$

Nesse caso, os elementos que permitem identificar a presença da cortesia ou não estão na cenografia ${ }^{3}$. Tal como aponta Briz, nesse espaço, a interpretação do que seja um mecanismo cortês ou descortês em relação às convenções é flexibilizado em virtude das estratégias da cenografia que podem confirmar a cena genérica como ampliar ou desconstruir essa cena trazendo formas limítrofes ao gênero ou outros gêneros, e, nesse caso, aos papeis desempenhados pelos enunciadores.

2 Tradução nossa: "(....) é uma estratégia linguística interacional, avaliada contexto a contexto, a cada momento, de acordo com o modo como a interação são iniciadas e, sobretudo, com as reações dos participantes na interação. Para a avaliação da cortesia verbal, propõe filtros de avaliação e de interpretação, que são ativados, desativados ou hierarquizados ao longo da interação: +/- solidariedade entre os interlocutores, +/- fim interpessoal da interação, +/pertinência de idiomas, +/- problematização temática y +/- aceitação linguística social" (A. Briz 2004: 79). Desta análise, conclui-se que, mesmo que uma forma linguística possa aparecer associada a uma estratégia cortês ou descortês, o efeito na interpretação pode variar, seja mantendo ou ainda potencializando o valor cortês ou descortês, seja desativando tal estratégia de modo que deixa de ser interpretada como mecanismo cortês o descortês, como sucede, por exemplo, na fala coloquial entre amigos jovens."

3 A cenografia, segundo Maingueneau (2004), "não é imposta pelo tipo ou pelo gênero de discurso, mas instituída pelo próprio discurso. (...) A cenografia tem por função fazer passar a cena englobante e a cena genérica para o segundo plano (...)" (MAINGUENEAU, 2004, p. 96) 
Nessa perspectiva, ao tomarmos o gênero escrito carta, tem-se um caso modelar para estudo desses mecanismos e de sua múltipla orientação. Duas são as principais razões para isso. A primeira é que se trata de um hipergênero, tal como Maingueneau denomina, ou seja, gênero que não sofreria restrições sócio-históricas existindo em vários grupos sociais, com variadas funções e cuja categorização se submeteria a restrições muito 'pobres' (MAINGUENEAU, 2010, p. 131). Na carta, esses elementos seriam a presença do destinatário e a do remetente em posições de abertura e fechamento do enunciado, acompanhada de poucas coerções referentes ao tema que se adequa à relação desenvolvida entre os interlocutores e aos objetivos do remetente. A segunda se refere a uma das características do gênero carta: o fato de que os envolvidos estão afastados por espaço e tempo, que se materializa na marcação ou indicação de como esses enunciadores compreendem a si e ao outro - iniciando o jogo das faces tal como na conversação, entendida nesse trabalho como Kerbrat-Orecchioni (2006) a caracteriza.

Como indica Costa (2009), em seu Dicionário de Gêneros Textuais,

há vários tipos de carta que possuem estruturas semelhantes, com alguns elementos básicos indispensáveis, como local e data, saudação, corpo, despedida e assinatura, ou específicos como cabeçalho, timbre, numeração, endereço, além dos anteriores, na correspondência comercial ou oficial (v. Ofício). Quanto à interlocução, a carta vai ser mais ou menos formal, dependendo do tipo de correspondência: comercial ou familiar. (....) O estilo do discurso se faz, então, num registro linguístico mais formal, a partir do próprio vocativo e das formas de tratamento no corpo da carta. (COSTA, 2009, p. 61, grifos nossos)

e, nessas formas de tratamento, começam a ser delineadas as relações de preservação (ou Face Flattering Acts - FFA) ou de ameaça à face (ou Face Threatening Acts - FTA) que, em geral, se estendem ou se explicitam no tratamento dado ao tema da carta, elemento central para a análise desenvolvida neste artigo sobre o papel do leitor.

As cartas são identificadas por sua função associada aos temas e aos espaços em que circulam. Mas, mesmo com esses elementos de identificação, muitos textos parecem se encaixar em mais de um subgênero do gênero carta. Este é o caso das cartas trocadas pelas personagens Charlô (antagonista / co-protagonista) com 
Linha D'Água (Online), São Paulo, v. 30, n. 2, p. 17-34, out. 2017

Felpo Filva (protagonista) do livro de mesmo título. Não deixam de ser cartas de leitor (não do leitor), algumas têm trechos que podem ser identificados como reclamação e outros como os de uma carta familiar em que o remetente demonstra certa intimidade, uma ligação mais próxima com o destinatário.

\section{A história de Felpo e o primeiro encontro com Charlô}

Há muitas formas de se conceber a personagem Felpo Filva, o protagonista do livro de Eva Furnari (2006), de mesmo nome. Nas primeiras páginas da narrativa, ele passa de um coelho que sofria com o tratamento das suas orelhas desiguais (pelo uso de um aparelho parecido com os de correção ortodôntica) e com o tratamento recebido dos colegas (zombarias), a um escritor e poeta, recluso, considerado por todos como um excêntrico.

Na Toca 88, da Rua Despinhos, na cidade de Rapidópolis, morava um coelho solitário. Ele não recebia visitas, não tinha amigos e nunca queria saber de conversa com ninguém.

Os vizinhos já estavam acostumados, diziam que ele vivia no mundo da lua, que era distraído e desligado, e que tudo isso se podia entender, pois ela era um poeta.

Era o famoso poeta e escritor Felpo Filva.

(FURNARI, 2006, p. 7)

O narrador nos apresenta Felpo por meio de uma descrição que identifica também como a posição de escritor é considerada no início da trama. A ele, muito era permitido, pois "era um poeta". Felpo, imbuído desse poder, encontra-se no momento de escrever sua autobiografia contando sobre suas desventuras quando a carta de Charlô chega:

Prezado Senhor Felpo Filva,

Meu nome é Charlô e admiro demais o seu talento e os seus poemas, mas se me permite, tem algunzinhos deles que eu não gosto nem um pouco. Sinceramente, 
eu discordei da história do poema da Princesa do avesso! Cruz Credo, que final pavoroso! (FURNARI, 2006, p. 12)

Se Felpo é legitimado pelos vizinhos que reconhecem a posição dele como escritor, Charlô se dá a conhecer como uma admiradora crítica, pois sua carta não é de um leitor seguidor, fã incondicional. Nessas primeiras linhas, apesar do respeito demonstrado ao poeta ("Prezado Senhor Felpo Filva") e dos mitigadores (ou suavizadores - softeners) (elogios: "admiro demais o seu talento e os seus poemas", pedido: "se me permite" e uso de diminutivo: "algunzinhos"), a leitora faz uma crítica severa em um ato ameaçador à face positiva (FTA): "tem algunzinhos deles que eu não gosto nem um pouco". Essa afirmação é acrescida da expressão interjectiva "Cruz Credo" e "que final pavoroso", dando a entender pela avaliação axiológica que deveria ser diferente.

A crítica de Charlô segue aliando os suavizadores a novos "ataques" (FTA): "Desculpe, senhor poeta, mas essa sua história é muito pessimista! Odiei esse final triste e dramático". Como se observa ao pedido de desculpas e ao pronome de tratamento que reconhece uma posição superior, a coelhinha alia uma outra posição marcada pela contrajunção (o uso do operador "mas") e pelos modificadores "pessimista, triste e dramático" em uma espécie de gradação. Por fim, apresenta, saindo da posição de leitora para a de escritora, um novo final que foi classificado como feliz por ela.

O final de Charlô tem cinco estrofes das quais transcrevemos a primeira e a segunda, esta por se apresentar paralela a de Felpo:

\begin{tabular}{l|l|l} 
O final de Felpo & O final de Charlô \\
$(\ldots)$ & $(\ldots) 1^{\mathrm{a}}$ & 2 $^{\mathrm{a}}$ \\
No fundo do poço & Um dia porém, & Do fundo do poço \\
com frio e com fome & a história mudou & Saíram cansados \\
os dois infelizes & ninguém sabe como & De tanta tristeza \\
para sempre serão & nem qual a razão. & De tanta prisão \\
(FURNARI, 2006, p. 12) & & $(\ldots .)$. \\
& & (FURNARI, 2006, p. 13)
\end{tabular}


Essa troca de papel, encenada pela nova versão do poema, é reforçada pelo ato de ameaça à face na pergunta final da carta: "O senhor gostou?". Esse ato de fala indireto pelo uso da pergunta, apesar de suavizador, mediado mais uma vez pelo pronome de tratamento "senhor", confere ao escritor a posição de leitor. Ao fim, é apresentado um procedimento acompanhante desarmador 4 :"Espero que o senhor não se ofenda com isso".

Esses atos mitigadores (suavizadores) podem aparecer de várias maneiras como afirma Benítez (2011):

Para minimizar este posible daño a la imagen del oyente, se recurre a los mitigadores (softeners) o procedimientos atenuativos, como los actos de habla indirectos, los desactualizadores modales, temporales o personales (condicional, pasado de cortesía, giro impersonal o pasivo), la lítotes, el eufemismo, las fórmulas de cortesía estereotipadas, los procedimientos reparadores (excusas y justificaciones), los modalizadores, los minimizadores, etc. ${ }^{5}$

Como foi possível observar nessa primeira carta, Charlô utiliza quase todos eles - inclusive no fechamento ("Um abraço cordial, Charlô Paspartu") ao retomar a deferência devida ao escritor.

A reação de Felpo foi questionar as ações de Charlô - primeiro quanto à legitimidade da leitora para fazer tal crítica e depois quanto ao questionamento relativo ao tom da sua obra: "Quem era aquela Charlô, que tinha coragem de falar com ele daquele jeito? E ainda mais mudar o fim da sua história? Felpo não ia nem responder a tamanho atrevimento! Amassou a carta e a jogou fora." (FURNARI, 2006, p. 14). Embora não seja parte da troca de cartas com Charlô, essa reação demonstra que Filva classifica o ato como ameaçador à face mesmo com os atenuadores. Isso pode ser encontrado no discurso indireto livre, em que a voz do

4 Trata-se de um procedimento subsidiário que "antecipa uma possível reação negativa do destinatário do ato, e se tenta neutralizá-la" (NASCIMENTO, 2016, p. 40)

5 Tradução nossa: "Para minimizar o dano possível à imagem do ouvinte, recorre-se aos mitigadores (softeners) ou a procedimentos atenuantes, como os atos de fala indiretos, os desatualizadores modais, temporais ou pessoais (condicional, passado de cortesia, voz passiva ou indefinido), a lítotes, o eufemismo, as fórmulas de cortesia estereotipadas, os procedimentos reparadores (desculpas e justificativas), os modalizadores, os minimizadores, etc." 
Linha D'Água (Online), São Paulo, v. 30, n. 2, p. 17-34, out. 2017

narrador se mistura com a do coelho poeta observado em expressões como "aquela Charlô" tendo como elemento mais saliente o uso do ponto de exclamação (tamanho atrevimento!) que indica a força ilocutória com que foi pronunciada essa frase.

Embora a resposta de Felpo tenha sido o silêncio, a crítica de Charlô se transforma em preocupação para o poeta: "A carta foi para o lixo, mas o assunto não. Felpo não conseguia esquecer as palavras de Charlô. Será que ela tinha razão? Será que ele era pessimista assim?" (FURNARI, 2006, p. 14). Os títulos dos livros de Felpo (A cenoura murcha, De olhos vermelhos, Um pé de coelho azarado, Infeliz Páscoa, A Horta por trás das grades), vistos agora com essa nova chave sugerida por Charlô, poderiam ser considerados pessimistas, foi a ponderação do coelho que, cedendo ao benefício da dúvida, retirou a carta do lixo.

Charlô, que havia saído da posição de leitora para a de crítica chegando a de co-escritora, um deslocamento que reforça a representação do leitor na obra aberta de $\mathrm{Eco}^{6}$, não recebendo resposta, escreve novamente a Felpo reafirmando a posição de leitora pautado pelo diálogo, como um interlocutor:

Prezado Poeta,

Como o senhor não me respondeu, estou escrevendo novamente. Sabe aquele seu poema, o do Passarinho na gaiola? Sinceramente esse aí falta um pouco de liberdade, de alegria e de imaginação!

\section{$(\ldots$.}

Eu tomei a liberdade de reescrever o seu poema soltando o passarinho.

Nessa segunda carta, Charlô se aproxima do escritor com o endereçamento "prezado poeta", ainda que esse seja uma espécie de fórmula para o gênero. Sua

6 Como Eco apresenta: "A noção de "obra aberta" não apresenta relevância axiológica. O espírito destes ensaios não é (alguém assim os entendeu, e depois sustentou virtuosamente a inaceitabilidade da tese) dividir as obras de arte em obras válidas ("abertas") e obras não válidas, obsoletas, feias ("fechadas"); acreditamos ter afirmado suficientemente que a abertura, entendida como ambiguidade fundamental da mensagem artística, é uma constante de qualquer obra em qualquer tempo." (ECO, 1991, p. 25) 
Linha D'Água (Online), São Paulo, v. 30, n. 2, p. 17-34, out. 2017

estratégia no todo da carta, no entanto, pouco se altera. Como não há necessidade de se identificar, ela apresenta o tema da carta, introduzido por um ato de fala indireto "Como o senhor não me respondeu" que insinua uma reprovação e justificativa para sua ação.

A presença do pronome de tratamento "senhor", que indica deferência, reforça a tentativa de justificar a crítica desabonadora ao tratamento temático do poema "Passarinho na Gaiola". As palavras de Charlô, nessa carta, parecem tentar a todo custo uma resposta de Felpo, configurando-se como uma provocação, que, para além dessa crítica, busca uma nova relação - a relação entre escritores. Como se observa no poema:

\begin{tabular}{l|l}
$\begin{array}{l}\text { Poema de Felpo } \\
\text { Passarinho na gaiola }\end{array}$ & $\begin{array}{l}\text { Poema reescrito por Charlô } \\
\text { Passarinho sem gaiola }\end{array}$ \\
Uma xícara tem asa & O cachorro tem osso \\
Passarinho também. & Passarinho também. \\
Uma xícara tem sorte & A janela tem grade \\
Passarinho não tem. & Passarinho não tem. \\
Uma casa tem canto & A cadeira tem pernas \\
Passarinho também. & Passarinho também \\
Uma casa tem planta & Uma lebre tem dentes \\
Passarinho não tem & Passarinho não tem. \\
O avião tem um bico & Frigideira tem ovos \\
Passarinho também. & Passarinho também \\
O avião tem o céu & Uma toca tem dono \\
Passarinho não tem. & Passarinho não tem.
\end{tabular}

O poema de Charlô, de tom eufórico, dialoga com o de Felpo, como sua contrapartida, um anti-poema. Essa relação se explicita como busca do escritor, de sua opinião, de uma ligação com ele, pela pergunta colocada logo após a apresentação do poema: "O senhor não acha que ficou mais interessante? Que o passarinho ficou bem mais solto e feliz?". Mesmo mantendo "senhor", o fechamento da carta 
é feito com "um abraço, Charlô", que parece apontar para uma aproximação encenada na carta e pretendida pela coelha.

A cenografia das duas cartas se assemelha - trata-se de uma mistura de carta de leitor com a troca de correspondência feita entre escritores mesmo que até esse ponto da narrativa a relação seja unilateral, um vir a ser. Nas duas cenografias, a letra cursiva e os desenhos a mão de Charlô corporificam proximidade e gentileza, oferecendo uma alternativa aos poemas para poder obter uma espécie de camaradagem, é a leitora-poeta que se configura, mas Felpo compreende como uma afronta a sua posição.

Ao receber a segunda carta, a reação do poeta se intensifica e ele datilografa a sua resposta com um desenho:

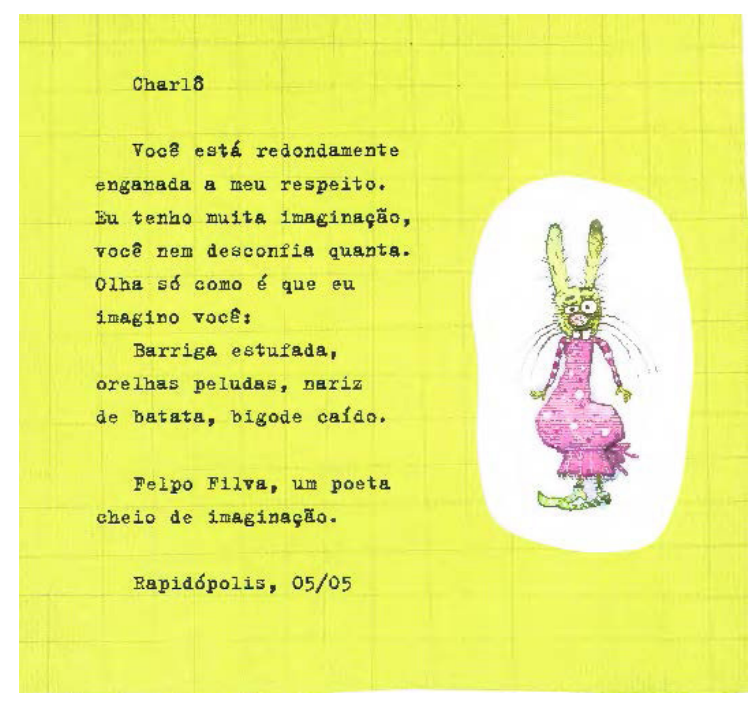

Charlô.

Você está redondamente enganada a meu respeito. Eu tenho muita imaginação, você nem desconfia quanta. Olha só como é que eu imagino você:

Barriga estufada, orelhas peludas, nariz de batata, bigode caído.

Felpo Filva, um poeta cheio de imaginação Rapidópolis, 05/05

Reprodução da carta de Felpo (FURNARI, 2006, p. 18)

Felpo elimina a possibilidade de uma relação respeitosa ao se endereçar a Charlô sem qualquer forma de tratamento, simplesmente adotando o primeiro nome da coelha. Em seguida, ataca a face negativa ao afirmar que ela estava enganada e ao trazer uma imagem depreciativa dela. Ao atacá-la, o poeta indica o que o havia incomodado: Charlô ferira sua autoestima de escritor ao classificá-lo como "poeta sem imaginação". 
Nas duas cartas, a percepção do coelho foi a de sofrer um desrespeito. Diferentemente de Charlô, a imagem de escritor era essencial para ele como havia sido anunciado no início da narrativa, uma vez que essa imagem permitira que ele encontrasse um lugar socialmente respeitado mesmo que de forma incomum como excêntrico.

O que se observa é que a imagem de leitor oferece menos riscos ao sujeito que a assume, já a imagem de escritor carrega a responsabilidade e certo poder, que, em muitos casos, os escritores não querem ver questionado. Como em qualquer outra profissão, ou ocupação, o que se espera é ser aprovado/a, obter reconhecimento pelo que se faz - e é esse ponto nevrálgico que Charlô tocou.

A coelhinha, por sua vez, não se sentiu atacada. A sua crítica não era dirigida a toda a obra de Felpo; ela se referira a apenas um poema como sem imaginação. Para Charlô, sem imaginação era o poema, sem alegria, sem liberdade que oprimia o ser descrito nos versos. Ela, como leitora, se envolvia com os temas de forma concreta, por essa razão libertara a princesa e o príncipe do poço, no poema "Princesa ao avesso"; pela mesma razão, libertara o passarinho.

As perguntas feitas por Charlô nas duas cartas revelam que, para ela, a poesia é algo sugerido pela experiência imediata do poeta, vem das suas emoções, empatias como as sugeridas pelos gregos em sua classificação da poesia pela mimese, como afirma Bordini:

\begin{abstract}
$\mathrm{Na}$ Antiguidade, a lírica esteve cercada de uma aura de expressividade direta, cedo amparada na emoção ou sentimento, como se a voz que se ouvia no poema fosse a do próprio poeta enquanto indivíduo histórico, enquanto as vozes encontradas nos contos, lendas, romances e dramas pareciam um artifício, afastando do texto a pessoa do poeta. (BORDINI, 2013, p. 25)
\end{abstract}

Dessa forma, a coelha propõe uma visão de mundo mais positiva, porque gosta do poeta e são sentimentos como esse que a guiam na elaboração de sua versão do poema. Por essa razão, ela, munida da imagem de Felpo, como alguém que confia, ignora sua provocação e responde à carta malcriada de Felpo com um telegrama, gênero que prima pela síntese, provocando o poeta de outra forma: 
Linha D'Água (Online), São Paulo, v. 30, n. 2, p. 17-34, out. 2017

$12 / 05$

Rapidópolis

POETA VG SE VOCE ACHA QUE SOU ASSIM VG VENHA CONFERIR PT VENHA TOMAR CHÁ COM BOLO DE CENOURA AQUI NA MINHA TOCA PT VOCE PODE MARCAR O DIA PT PIOR CEGO É AQUELE QUE NÃO QUER VER A SUA PROPRIA IMAGINAÇÃO PT CHARLÔ

(FURNARI, 2006, p. 19)

Diferentemente das cartas, no telegrama, a provocação se dirige à face positiva do poeta ("se você acha que sou assim, venha conferir") de forma explícita. Acrescenta-se a isso, o ato indireto "Pior cego é aquele que não quer ver a sua própria imaginação" em que a coelhinha instiga o poeta de outra forma, pedindo para que ele revise a forma como imagina seus poemas, seus textos. No fechamento do telegrama, pela necessidade da síntese imposta pelo gênero ou pela proposta de uma relação mais próxima, Charlô assina com seu nome somente.

Felpo que já estava completamente tomado pela dúvida se havia respondido de modo acertado, fica muito nervoso com todas as possibilidades apresentadas por Charlô, principalmente pela proposta de contato pessoal e tem até que recorrer a remédios para acabar com a tremedeira subsequente (o famoso destremil, FURNARI, 2006, p. 21). Depois de muito pensar, ele escreveu uma carta longa com uma fábula, a da Lebre e da Tartaruga, para exemplificar sua situação. Nessa missiva, o tom se modifica completamente:

Charlô,

Gostei muito da sua sinceridade. Eu também quero ser sincero como você e é por isso que vou the dizer logo que tenho muitos defeitos (grandes e enormes). Para explicá-los vou contar uma fábula.

$(\ldots)$

GEBARA, A. E. L.; SPARANO, M. E. 0 papel do leitor em Felpo Filva, de Eva Furnari 
Linha D'Água (Online), São Paulo, v. 30, n. 2, p. 17-34, out. 2017

O poeta aceita na carta a relação de proximidade ao fazer uso da polidez positiva, ("gostei muito da sua sinceridade"). Depois da fábula, ao se desculpar por não poder aceitar o convite, observa-se, mais uma aproximação por um ato de fala indireto que tem como objetivo preservar novamente a face de Charlô e, dessa vez, a própria - por ele ser um coelho com alma de tartaruga, talvez eles nunca se encontrem.

Enquanto Felpo começa a escrever "poemas, textos, frases" chegando até a escrever um conto de fadas, descobre-se capaz de se divertir com suas criações. $\mathrm{O}$ coelho está ansioso pela resposta de Charlô que se mostra compreensiva e acolhedora. Dessa vez, não há mais atos de ameaça à face, mas atos de preservação tais como os utilizados por Felpo.

Poeta,

Fiquei muito comovida com sua carta.

Felpo querido, eu gosto de orelhas diferentes, acho que dão um charme interessante a um coelho. Principalmente você, que é poeta, devia se orgulhar de ser assim, especial.

Bem, Felpo, foi lindo e corajoso confessar que tem alma de tartaruga, afinal elas são cheias de sabedoria.

Bem, Felpo, agora admiro não só os seus poemas, mas também a sua pessoa. Quando você quiser vir tomar chá comigo será muito bem-vindo.

Beijos

Charlô

(FURNARI, 2006, p. 27)

O fechamento da carta alinha Charlô a uma nova posição, de leitora para alguém mais próximo do escritor, acrescenta essa posição a já existente; o que é 
Linha D'Água (Online), São Paulo, v. 30, n. 2, p. 17-34, out. 2017

possível perceber pela declaração que ela faz para Felpo: "Bem, Felpo, agora admiro não só seus poemas, mas também a sua pessoa."

Um relacionamento se estabelece entre os dois, e o poeta, com a desculpa de enviar a receita do bolo, escreve nova carta, da qual destacamos a abertura e o fechamento.

Charlô,

Estou enviando a receita da minha avó.

Espero que você goste tanto quanto eu.

Você também escreve poemas?

Beijos

Felpo

R. 27/05

(FURNARI, 2006, p. 28)

Neles, é possível observar a mudança de tratamento e de posição. O endereçamento inicial mostra intimidade; a pergunta antes do fechamento indica que Felpo a considera capaz de ser um igual e a despedida retoma a intimidade inicial. Essa forma de interação se desenvolve e após alguns desencontros a la comédia de erros, eles se encontram, se apaixonam e se casam.

\section{Leitor, escritor na mesma página}

$\mathrm{Na}$ narrativa, o papel do leitor se constitui como elemento que faz a trama se desenvolver e se apresenta de várias formas permitindo que seja observado como esse papel é definido a partir da concepção de leitura como prática social.

Como isso acontece na história? Os elementos são: 
Linha D'Água (Online), São Paulo, v. 30, n. 2, p. 17-34, out. 2017

- a passagem da cortesia negativa para a positiva: os primeiros encontros de Charlô e Felpo, mediados por carta, eram pautados pela cortesia negativa, em atos de ameaça à face, algumas vezes, com atenuadores. Isso ocorreu, porque Charlô, desde o princípio, saiu da posição de leitor mais tradicional, buscando a posição de leitor que pode interferir na obra ao explicitar sua opinião para o escritor. A base é a admiração do leitor pelo escritor, mas nem sempre essa admiração impede que se questione ou se $\operatorname{produza}(\mathrm{m})$ texto(s) alternativo(s) que agradem a certos segmentos de leitores. Um exemplo desse fenômeno atualmente é o da Fanfiction ${ }^{7}$, outro são os poemas da coelha da narrativa. Os contatos entre leitor e escritor, como no caso das personagens do livro, se beneficiam quando da cortesia negativa passa-se à positiva, que se traduz na maioria das vezes na possibilidade de diálogo entre ambas as posições.

- a passagem do gênero carta formal para carta pessoal: o posicionamento dos participantes nas ações criadas em um gênero varia de acordo com a função e os limites a ele atribuídos. Assim na narrativa, a passagem da carta formal para carta informal entre conhecidos explicita um novo papel de leitor que não é mantido à distância pelo escritor, mas ouvido.

- $\quad$ o deslocamento de Felpo que aceita perder o poder de escritor para interagir com o leitor como seu igual: no momento em que se instaura a dúvida em Felpo sobre como tratar Charlô; se ela era capaz de compreender o que era ser um escritor; se ela era leitora como ele acreditava que devia ser (que pensa sobre a obra de maneira respeitosa), observa-se a mudança na forma de cortesia também. O tratamento ao outro e o posicionamento atribuído a esse outro é uma das maneiras de se conceber o que seja o leitor, qual seu poder e sua atuação em relação ao texto. Ao fim do livro, uma imagem de leitor mais próximo do autor e mais atuante se solidifica.

- o deslocamento do dominio discursivo literário para o dominio discursivo privado: depois da segunda carta, a relação tradicional entre leitor e escritor foi rompida. Felpo demonstra aceitar o deslocamento do domínio discursivo literário para o domínio discursivo privado e se apresenta como um coelho

Sobre a fanfiction, gênero que "não apresenta caráter comercial nem lucrativo, pois são escritos por fãs que se utilizam de personagens ficcionais já existentes." (ALVES, 2015, p. 16). 
com defeitos que se abre à possibilidade de um encontro. Percebe-se que, pela interação leitor e escritor e pela insistência de Charlô com seus poemas, Felpo reconheceu seu valor ("Leu de novo a versão dela para o poema do passarinho. Hum, o resultado não estava tão mal assim. Ele tinha que admitir que a Charlô possuía um certo talento para escrever e que tinha até um certo senso de humor, era divertida." (FURNARI, 2006, p. 19) e aceitou que ela partilhasse de outras áreas de sua vida. $\mathrm{O}$ movimento se configura a partir de competências do leitor: compreender as técnicas da escrita; compreensão das coerções do processo de escrita literária; demonstrar respeito pela posição de escritor. Mesmo que a amizade como as dos personagens não se efetive, uma relação mais horizontal se instaura.

- o tempo estabelecido pelo contato por carta: Seara (2010) afirma que esse gênero traz duas questões desde sua concepção: o da ausência, característica geral, uma vez que a carta marca a distância entre os interlocutores; e outra, que Seara aplica à carta de amor, e que entendemos também como característico de todas as cartas que estabelecem - mesmo que por força unilateral - uma aproximação entre seus envolvidos, é a abolição do tempo em prol de um presente permanente. Assim Charlô e Felpo se sentiram e essa presença no presente fez com que a reflexão sobre o outro impulsionasse a tomada de decisão e a mudança. Manter o outro sob o foco nesse presente permanente permite que se questione a própria posição também.

Assim, o papel do leitor passa de tradicional, de caráter mais passivo, para um leitor ativo, interlocutor pleno. Por sua vez, o escritor sai de sua posição acima dos outros para dialogar dentro da visão de obra aberta e de leitura como prática social, em que sujeitos em condições sócio-históricas definidas no domínio discursivo literário interagem trocando de posições sem trocar de papel.

\section{Referências}

ALVES, E. C. de A. Fanfiction e Práticas de Letramentos na Internet. Campinas, SP: Pontes Editores, 2015. 
Linha D'Água (Online), São Paulo, v. 30, n. 2, p. 17-34, out. 2017

BÉNITEZ, D. M. Distintas funciones de la descortesía: los insultos de los políticos en la prensa escrita (pdf). In Linguística en la red. N. IX. 30-10-2011. Disponível em http://www.linred.es/ numero9_articulo_7.html. Acesso em 29 set. 2017.

BORDINI, M. da G. Aproximações à lírica. In: BARBOSA, M. H. S.; BECKER, P. (Orgs.) $A$ poesia que se escreve, a poesia que se lê. Passo Fundo: Ed. Universidade de Passo Fundo, 2013.

COSTA, S. R. Dicionário de gêneros textuais. 2 ed. rev. e ampl. Belo Horizonte: Autêntica Editora, 2009.

ECO, U. Obra aberta: forma e indeterminação nas poéticas contemporâneas. 8. ed. Tradução de Giovanni Cutolo. São Paulo: Perspectiva, 1991.

FURNARI, E. Felpo Filva. 4a impressão. São Paulo: Moderna, 2006 (Coleção Girassol). Ilustrações da autora.

KERBRAT-ORECCHINI, C. ¿Es universal la cortesia? Trad. Silvia Kaul de Marlangeon. In BRAVO, D.; BRIZ, A. (orgs.) Pragmática Sociocultural: Estudos sobre el discurso de cortesia em español. Barcelona: Ariel, 2004.

- Análise da Conversação: princípios e métodos. Tradução Carlos Piovesan Filho. São Paulo: Parábola Editorial, 2006.

MAINGUENEAU, D. "Hipergênero, gênero e internet". Trad. Maria Inês Otranto. In. Doze conceitos em Análise do Discurso. Maria Cecília Perez de Souza-e-Silva; Sírio Possenti (Orgs.). São Paulo: Cortez, 2010.

. Verbete Cena de enunciação. In CHARAUDEAU, P.; MAINGUENEAU, D.

(Orgs.). Dicionário de análise do discurso. Coordenação de tradução Fabiana Komesu. São Paulo: Contexto, 2004.

MARCOTULIO, L.L.; SOUZA, S. L. A teoria da polidez de Brown e Levinson aplicada ao português brasileiro: Desafios e propostas. In Anais do IX Semana Nacional de Estudos Filológicos e Linguísticos - SENEFIL, Círculo Fluminense de Estudos Filológicos e Linguísticos, Departamento de Letras da FFP / UERJ, 2007. Disponível em http://www.filologia.org.br/ ixsenefil/anais/07.htm Acesso em 30 nov. 2014. 
Linha D'Água (Online), São Paulo, v. 30, n. 2, p. 17-34, out. 2017

NASCIMENTO, J. dos S. Relações de sexo/gênero e polidez linguistica na fala de universitários de Lagarto/SE. Orientadora: Leilane Ramos da Silva. 109 f. Dissertação. Universidade Federal de Sergipe. 2016. pdf.

SEARA, I. R. Confissão intimista na correspondência amorosa de António Lobo Antunes: estudo pragmático. In MARÇALO, M. J.; LIMA-HERNANDES, M. C.; ESTEVES, E.; FONSECA, M. do C.; GONÇALVES, O.; VILELA, A. L.; SILVA, A. A. Lingua Portuguesa: ultrapassar fronteiras, juntar culturas (pdf). Évora: Universidade de Évora, 2010.

Recebido em 13/10/2017.

Aprovado em 17/10/2017. 
Linha D'Água (Online), São Paulo, v. 30, n. 2, p. 17-34, out. 2017 